\title{
Thyrotropin Suppressive Therapy in Differentiated Thyroid Cancer
}

\section{Yan-Li Xue, Zhong-Ling Qiu and Quan-Yong Luo*}

Department of Nuclear Medicine, Shanghai Sixth People's Hospital, Shanghai Jiao Tong University, Shanghai 200233, China

Differentiated thyroid carcinoma (DTC) is the most frequent endocrine tumor, and its incidence has increased significantly in recent years [1]. Total or near thyroidectomy and radioiodine ablation followed by thyroxine suppression of thyrotropin (TSH) is an effective and acceptable therapeutic scheme for most DTC patients [2,3]. The preferred drug of TSH suppressive therapy is levothyroxine (L-T4). L-T4 treatment reduces serum TSH level, thereby inhibiting the growth of residual neoplastic tissue, suppressing serum Tg level and reducing tumor recurrence and progression in DTC patients. However, excessive TSH suppression therapy can induce exogenous subclinical hyperthyroidism that may adversely affect the skeletal [4] and cardiovascular systems $[5,6]$. All those would affect the quality of life of patients with DTC. So far, there is still no consensus about the optimal serum TSH levels that is required for the initial treatment and follow-up of DTC despite several guidelines recommended the TSH suppressive levels. In high-risk patients who have persistent disease, the American Thyroid Association (ATA) and European Thyroid Association (ETA) recommend that the serum TSH level be kept at $<0.1 \mathrm{mU} / \mathrm{L}$. In higherrisk but disease-free patients, the ATA recommends TSH levels be kept at $0.1-0.5 \mathrm{mU} / \mathrm{L}$ for 5-10 years, whereas the ETA recommends TSH levels $<0.1 \mathrm{mU} / \mathrm{L}$ for 3-5 years. In low-risk patients, the initial serum TSH levels should be kept at 0.1-0.5 mU/L in the ATA guidelines and $<0.1 \mathrm{mU} / \mathrm{L}$ in the ETA guidelines. In low-risk and disease-free patients on follow-up, ATA and ETA both recommend serum TSH level be kept in the low normal range $(0.3-2.0 \mathrm{mU} / \mathrm{L})[7,8]$.

In recent years, the concept of TSH-suppressive therapy has gradually changed, which recommends to take into account both the risk of recurrence or progression of DTC and the risk from adverse effects of L-T4 therapy. The risk for recurrence and progression in patients with DTC can be divided into three levels: low, intermediate and high risks, according to the ATA guidelines [7], and a similar assessment of the risk of adverse effects of L-T4 suppressive therapy can be also divided into low, intermediate and high risks, summarized by Biondi and Cooper [9]. This can be called "double-risk-adapted strategy". This approach provided differing TSH suppression levels for both initial treatment (in the 2-3 years after radioiodine treatment at our department) and follow-up. We support the risk-adapted strategy for L-T4 therapy in DTC patients. It is reasonable and constructive.

According to the double-risk-adapted strategy, suggested TSH levels in patient with DTC at initial treatment is as follow. In patients with high or intermediate risk of recurrence or progression and no matter what risk of L-T4 related adverse effects, serum TSH levels should be kept undetectable $(<0.1 \mathrm{mU} / \mathrm{L})$. However, in patients with a high or intermediate risk of tumor progression and a high or intermediate risk of adverse effects from L-T4, the degree of TSH suppression should be adapted to the clinical situation, and cardiologic evaluation and bone density assessment should be underwent periodically $[10,11]$. Calcium and vitamin D are benefit for osteoporosis patients, especially for postmenopausal patients [12]. In patients with a low risk of cancer recurrence or progression and a high or intermediate risk of adverse effects, a TSH level of $0.5-1.0 \mathrm{mU} / \mathrm{L}$ would be reasonable. A TSH level of $0.1-0.5 \mathrm{mU} / \mathrm{L}$ is suggested in patients with a low risk of tumor recurrence and a low risk of adverse effects.
According to the double-risk-adapted strategy, suggested TSH levels in patient with DTC during follow-up is as follow. In high-risk patients with persistent or metastatic disease, no matter what risk type from L-T4, TSH levels should be kept undetectable $(<0.1 \mathrm{mU} / \mathrm{L})$. In high-risk patients and disease free for 5-10 years, no matter what risk type from L-T4, whose serum TSH levels at $0.1-0.5 \mathrm{mU} / \mathrm{L}$ should be considered. In those patients with high risk from L-T4, the degree of TSH suppression level should be adapted to the clinical situation. In patients with intermediate risk from L-T4, cardiovascular drugs, calcium, and vitamin $\mathrm{D}$ should be considered. In patients with an intermediate risk for cancer recurrence or progression and high or intermediate risk of adverse effects from L-T4, the degree of TSH suppression should be dynamically monitored and modified according to clinical assessment. After 5-10 years of follow-up if serum Tg is undetectable and there is no clinical evidence of disease, a TSH level of 1.0-2.0 mU/L is advisable. In disease-free low-risk DTC patients during follow-up, the TSH level at 1-2 mU/L is appropriate in patients with high or intermediate risk of adverse effects. In patients with a low risk of adverse effects, the TSH level at the low normal range $(0.3-2.0 \mathrm{mU} / \mathrm{L})$ is advisable.

In all, the benefit and the risk of the adverse effects of L-T4 suppressive therapy for DTC patients should be carefully balanced in clinical practice. TSH suppressive level should be modified according to clinical assessment and be individualized against the potential for adverse effects according to the double-risk-adapted strategy for L-T4 suppressive therapy. More aggressive TSH suppression is advisable in patients with high-risk of cancer recurrence or progression, whereas less aggressive TSH suppression is reasonable in low-risk DTC patients.

\section{References}

1. Siegel R, Naishadham D, Jemal A (2012) Cancer statistics, 2012. CA Cancer J Clin 62: 10-29.

2. Robbins RJ, Schlumberger MJ (2005) The evolving role of (131)I for the treatment of differentiated thyroid carcinoma. J Nucl Med 46: 28S-37S.

3. Campos M, van Hoek I, Peremans K, Daminet S (2012) Recombinant human thyrotropin in veterinary medicine: current use and future perspectives. J Vet Intern Med 26: 853-862.

4. Leese GP, Flynn RV (2011) Levothyroxine dose and fractures in older adults. BMJ 342: d2250.

5. Biondi B, Cooper DS (2008) The clinical significance of subclinical thyroid dysfunction. Endocr Rev 29: 76-131.

6. Biondi B, Palmieri EA, Klain M, Schlumberger M, Filetti S, et al. (2005) Subclinical hyperthyroidism: clinical features and treatment options. Eur $J$ Endocrinol 152: 1-9.

*Corresponding author: Quan-yong Luo, Department of Nuclear Medicine Shanghai Sixth People's Hospital, Shanghai Jiao Tong University, 600 Yishan Rd, Shanghai 200233, China, E-mail: Iqyn@sh163.net

Received December 21, 2012; Accepted December 26, 2012; Published December 28, 2012

Citation: Xue YL, Qiu ZL, Luo QY (2013) Thyrotropin Suppressive Therapy in Differentiated Thyroid Cancer. Altern Integ Med 2: e106. doi:10.4172/2327-5162.1000e106

Copyright: ( 2013 Xue YL, et al. This is an open-access article distributed under the terms of the Creative Commons Attribution License, which permits unrestricted use, distribution, and reproduction in any medium, provided the original author and source are credited. 
Citation: Xue YL, Qiu ZL, Luo QY (2013) Thyrotropin Suppressive Therapy in Differentiated Thyroid Cancer. Altern Integ Med 2:e106. doi:10.4172/2327$5162.1000 \mathrm{e} 106$

7. American Thyroid Association (ATA) Guidelines Taskforce on Thyroid Nodules and Differentiated Thyroid Cancer, Cooper DS, Doherty GM, Haugen BR, Kloos RT, et al. (2009) Revised American Thyroid Association management guidelines for patients with thyroid nodules and differentiated thyroid cancer. Thyroid 19: 1167-1214

8. Pacini F, Schlumberger M, Dralle H, Elisei R, Smit JWA, et al. (2006) European Thyroid Cancer Taskforce European consensus for the management of patients with differentiated thyroid carcinoma of the follicular epithelium. Eur $\mathrm{J}$ Endocrinol 54: 787-803.

9. Biondi B, Cooper DS (2010) Benefits of thyrotropin suppression versus the risks of adverse effects in differentiated thyroid cancer. Thyroid 20: 135-146.
10. Biondi B, Fazio S, Carella C, Sabatini D, Amato G, et al. (1994) Control of adrenergic overactivity by beta-blockade improves the quality of life in patients receiving long term suppressive therapy with levothyroxine. J Clin Endocrinol Metab 78: 1028-1033.

11. Gullu S, Altuntas F, Dincer I, Erol C, Kamel N (2004) Effects of TSH-suppressive therapy on cardiac morphology and function: beneficial effects of the addition of beta-blockade on diastolic dysfunction. Eur J Endocrinol 150: 655-661.

12. Kung AW, Yeung SS (1996) Prevention of bone loss induced by thyroxine suppressive therapy in postmenopausal women: the effect of calcium and calcitonin. J Clin Endocrinol Metab 81: 1232-1236. 